\title{
Terra: revelação e dádiva (Êxodo 6,2-8)
}

\author{
Land: revelation and gift (Exodus 6,2-8)
}

Júlio Paulo Tavares Mantovani Zabatiero*

\author{
* Doutor em Teologia pelas \\ Faculdades EST, Mestre em \\ Teologia pelas Faculdades \\ EST. Professor na Faculdade \\ Teológica Sul-Americana, \\ Londrina, Brasil. \\ juliopauloz@hotmail.com
}

Recebido em: 30/10/2021

Aprovado em: 11/11/2021

Licença Creative Commons CC BY 4.0
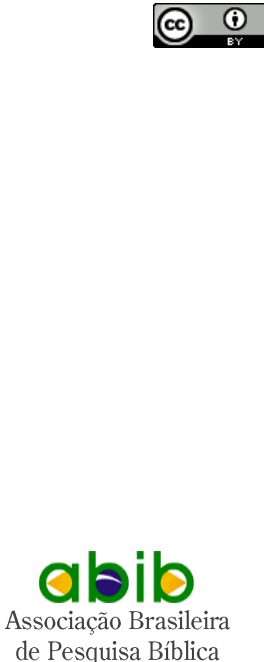

\begin{abstract}
Resumo
$\mathrm{O}$ artigo versa sobre o cuidado da terra como expressão de uma nova visão da propriedade e posse dos bens. A partir da busca por outros mundos possíveis, apresenta uma exegese de Êxodo 6,2-8 que destaca os seus temas principais: a revelação de YHWH e a libertação dos israelitas para uma nova e digna vida na terra dada por YHWH a seu povo. Sua hipótese básica é que a perícope manifesta a voz do campesinato judaíta no processo de reorganização de Judá sob o período da dominação persa e na consequente composição da forma normativa do Pentateuco (Torá). Sua inspiração hermenêutica vem da leitura popular da Bíblia e sua metodologia exegética se assemelha à chamada Crítica da Redação, com ênfase para o papel da memória sociocultural na composição de textos.
\end{abstract}

Palavras-chave: Revelação. Aliança. Terra. Dádiva. Libertação.

\begin{abstract}
The article deals with land care as an expression of a new vision of ownership and possession of assets. Inspired by the search for other possible worlds, it presents an exegesis of Exodus 6:2-8 that highlights its main themes: the revelation of YHWH and the liberation of the Israelites for a new and dignified life on the earth given by YHWH to his people. Its basic hypothesis is that the pericope manifests the voice of the Judahite peasantry in the process of reorganization of Judah under the period of Persian domination and in the consequent composition of the normative form of the Pentateuch (Torah). Its hermeneutic inspiration comes from the popular reading of the Bible and its exegetical methodology is akin to the so-called Critique of Redaction, with an emphasis on the role of sociocultural memory in the composition of texts
\end{abstract}

Keywords: Revelation. Covenant. Land. Gift. Liberation.

\section{Introdução}

Como cuidar de uma terra que não é nossa? Como cuidar de uma terra que é objeto de exploração econômica que suga até seus últimos recursos e a abandona como um deserto improdutivo? Como cuidar da terra em uma sociedade globalizada de modo neoliberal, predatório e desumano? Somente a partir de uma radical mudança de modo de pensar 
e praticar a posse e o cuidado da terra. Terra, não só enquanto planeta, não só enquanto espaço de moradia, também como lugar de cultivo, cultura, culto.

Neste artigo retomamos um dos textos fundantes da teologia latino-americana da libertação, o livro do Êxodo, especificamente a perícope de 6,2-8. Nos tempos originários da leitura popular da Bíblia, o livro do Êxodo foi a nossa principal fonte de inspiração, fonte de ânimo e empoderamento para enfrentar a dominação capitalista liberal, para propor uma nova sociedade brasileira, democrática e justa. Sob o eixo da transformação estrutural agrupamos muitas lutas e muitos sonhos. Construímos um novo modo de ler a Bíblia que, sem rejeitar a academia, deslocou o eixo da interpretação para a comunidade eclesial em busca de libertação. Estudos Bíblicos foi um dos marcos dessa caminhada exegética inovadora e contestatória.

Este artigo é escrito no espírito que animou a fundação de Estudos Bíblicos e se alimentou da experiência das comunidades eclesiais ecumênicas e movimentos sociais libertários. O olhar acadêmico está presente, mas submetido ao olhar popular, ao olhar da luta por libertação, ao olhar de quem cuida de fato da terra, mesmo quando a terra não é sua. Olhar plural, ecumênico, multiepistêmico, contestatório, não colonial, não elitista. Seu objetivo é apontar para as contribuições de uma pequena porção da Escritura para o debate emancipatório da atualidade. Ao fazê-lo, porém, também sugere alguns questionamentos à prática acadêmica da exegese com quem dialoga livremente. O texto é lido a partir de seu lugar literário e contextual e a decisão primária de sua leitura é pelo mundo persa-helenístico da forma 'final' do Pentateuco. Reconhece a importância da pesquisa genealógica do Pentateuco, mas vê como prioridade (jamais como exclusividade) a leitura do Pentateuco como uma obra coletiva e emancipatória do povo de Israel debaixo da dominação imperial.

Cuidar da terra só é possível de fato quando constatamos e reconhecemos que a terra não é verdadeiramente nossa. Usando a linguagem da perícope em diálogo com a jurídica contemporânea, podemos dizer que Deus nos dá a posse, mas não a propriedade da terra, que lhe pertence - e porque lhe pertence, pertence a todos os seres vivos do planeta, não apenas ao ser humano que a domina e usa para seus próprios fins. Assim como a terra não é nossa, também a Bíblia não é propriedade privada de nenhum de nós. Na metáfora de Carlos Mesters, a Bíblia é a casa do povo e é nessa casa que pedimos licença para entrar e papear.

\section{Tradução, estruturação e lugar textual da perícope}

${ }^{2}$ E Deus disse a Moisés: Eu sou YHWH. ${ }^{3}$ Apareci a Abraão, a Isaque e a Jacó como 'El-Shaday'; mas meu nome, YHWH, não foi conhecido por eles. ${ }^{4}$ Também firmei com eles a minha aliança, para dar-lhes a terra de Canaã, a terra em que habitaram como migrantes. ${ }^{5}$ Agora ouço os gemidos dos israelitas, escravizados pelos

1 Mantive o nome de Deus sem tradução, apenas transliterado. Não há consenso entre os estudiosos sobre o sentido do nome hebraico. A escolha tradicional das edições bíblicas, Deus TodoPoderoso, não tem qualquer base no idioma hebraico. Uma tentativa de tradução mais adequada foi proposta por alguns estudiosos: o Deus da montanha, mas também não ganhou ampla aceitação na pesquisa. Não é tão importante assim sabermos exatamente o sentido do nome, para compreender o texto bíblico basta sabermos que era um dos nomes usados pelos pais e mães de Israel na antiguidade israelita. A bibliografia sobre este nome é bastante ampla. Pode-se começar a pesquisa com os dicionários teológicos do Antigo Testamento. 
egípcios, e me lembrei da minha aliança. ${ }^{6}$ Portanto, dize aos israelitas: eu sou YHWH e vos tirarei de debaixo dos pesados encargos do Egito, e vos libertarei de vossa escravidão, e vos resgatarei com braço estendido e com grandes atos de justiça. ${ }^{7}$ Tomar-vos-ei por meu povo e serei vosso Deus. Então, sabereis que eu sou YHWH, vosso Deus, que vos tiro de debaixo do pesado trabalho no Egito. ${ }^{8} \mathrm{E}$ vos levarei à terra a qual jurei dar a Abraão, a Isaque e a Jacó; e vo-la darei para a possuirdes. Eu sou YHWH.

Para entender bem um texto bíblico sempre é importante perceber como ele é estruturado e qual é o seu lugar no livro de que faz parte ${ }^{2}$. Esta perícope possui uma estrutura quiástica (na forma de $\mathrm{X}$ ) e tem no seu centro a definição do tema principal ${ }^{3}$. A seguir veja uma forma gráfica da estrutura:

${ }^{2}$ E Deus disse a Moisés:

Eu sou YHWH.

${ }^{3}$ Apareci a Abraão, a Isaque e a Jacó como 'El Shaday; mas meu nome, YHWH, não foi conhecido por eles.

${ }^{4}$ Também firmei com eles a minha aliança, para dar-lhes a terra de Canaã, a terra em que habitaram como migrantes.

${ }^{5}$ Agora ouço os gemidos dos israelitas, escravizados pelos egípcios, e me lembrei da minha aliança.

${ }^{6}$ Portanto, dize aos israelitas: eu sou YHWH

e vos farei sair de debaixo dos pesados encargos do Egito, e vos libertarei de vossa escravidão, e vos resgatarei com braço estendido e com grandiosas sentenças judiciais.

${ }^{7}$ Tomar-vos-ei por meu povo e serei vosso Deus. Então, sabereis que eu sou YHWH, vosso Deus, que vos faço sair de debaixo do pesado trabalho no Egito.

${ }^{8} \mathrm{E}$ vos farei entrar ${ }^{4}$ na terra a qual jurei, levantando a mão ${ }^{5}$, dar a Abraão, a Isaque e a Jacó;

e vo-la darei para a possuirdes.

Eu sou YHWH.

2 Esta decisão metodológica é mais tipicamente ocidental-do que cultural-judaica, cujos antigos rabinos liam perícopes em relação com outras tematicamente afins, independentemente de estarem no mesmo livro. Ver Sommer (2016, p. 1091-1108). A própria seleção do parágrafo a ser examinado (2-8) já pressupõe uma escolha, posto que ele pertence a uma subseção maior do livro, possivelmente 5,22-6,13.

3 Não é possível ter certeza plena a respeito dos arranjos estruturais de várias perícopes da Escritura. Sobre esta, ver a discussão em Medina (2005).

4 Não é a tradução usual do verbo hebraico, mas optei por ela aqui a fim de formar um jogo de palavras com a expressão "vos faço sair" no verso anterior.

5 A expressão no hebraico é simplesmente "levantei a mão", metáfora para o juramento. Mantive a expressão aqui para indicar o elo com a expressão "braço estendido" no verso 6 . 
O centro da estrutura é o verso 6a que repete a expressão eu sou YHWH (versos 2, 7 e 8, com o nome YHWH também usado no verso 3). A estrutura e a repetição da expressão e do nome divino mostram que o tema principal da perícope é a autorrevelação do nome de Deus para os israelitas no Egito. Os versos 3 e 8 estão ligados estruturalmente pela presença de Abraão, Isaque e Jacó, primeiro como pessoas que receberam a manifestação de Deus, depois como aquelas que receberam a promessa (juramento) da terra da parte de Deus. Os versos 4 e 7 estão ligados pelo tema da aliança: no v. 4 a aliança com os pais e mães de Israel, que incluía a promessa da terra, enquanto no v. 7 o texto atualiza a aliança com a geração do Êxodo e vincula a promessa da terra com a saída do Egito e com o conhecimento do nome de Deus (retomando um tema do verso 3). Os versos 5 e $6 \mathrm{~b}$ estão ligados pelo tema da escravidão e libertação do Egito - o verso 5 mencionando o grito dos israelitas escravizados e o verso $6 \mathrm{~b}$ descrevendo a ação libertadora de YHWH como cumprimento da aliança de que YHWH se lembra no verso 5. Os versos $2 \mathrm{~b}$ e $8 \mathrm{~b}$ formam a moldura com a expressão "eu sou YHWH".

Esta estrutura mostra que a perícope estabelece uma ligação entre temas importantes do livro do Êxodo e de todo o Pentateuco: a promessa da terra aos pais e mães de Israel, a aliança de YHWH com os pais e mães e sua descendência (reafirmada com relação à geração do Êxodo), a libertação do Egito e o conhecimento de Deus e seu nome YHWH. ${ }^{6}$ Ao mesmo tempo, ela ajuda a entender o lugar da perícope no livro do Êxodo (e no Pentateuco). Há quase que uma repetição de Ex 3,1ss, o relato do chamado de Moisés por YHWH para tirar o povo do Egito. Alguns dos temas desta perícope já estavam presentes no chamado de Moisés: (a) a revelação do nome YHWH, desconhecido dos pais e mães de Israel e desta geração do Êxodo, versos 13-15; (b) a menção de Abraão, Isaque e Jacó, versos 6, 15 e 16; (c) a ação libertadora de YHWH que tirará, com Moisés, os israelitas do Egito e os levará à terra (mas sem referência à promessa da terra aos pais e mães de Israel), versos 7-12 e 17; (d) Moisés fala aos anciãos de Israel, mas não há menção à resposta deles, aparentemente positiva.

Ex 6,2-8 é estrategicamente colocado na narrativa após os primeiros contatos entre Moisés e o faraó do Egito, a partir dos quais os trabalhos forçados a que eram submetidos os israelitas foram ainda mais pesados - é esse recrudescimento da opressão que motiva a resposta incrédula dos israelitas em 6,9. Olhando adiante no Êxodo, esta perícope serve como justificativa para as pragas contra o faraó e o Egito, uma demonstração impressionante do poder de YHWH, cujo propósito pode ser visto como o de reacender a fé dos israelitas em seu Deus. Olhando ainda mais adiante no livro do Êxodo e em Levítico e Números, a perícope também serve como introdução a um tema recorrente do Pentateuco: a inconstância (infidelidade) dos israelitas. YHWH permanece fiel à aliança que estabeleceu com os pais e mães de Israel, mas esta geração do Êxodo é inconstante e infiel,

6 A união desses temas é trabalho do grupo de escribas ligados ao sacerdócio, responsáveis pela elaboração do chamado escrito sacerdotal ( $\mathrm{P}$ na linguagem acadêmica), uma das fontes usadas para a escrita do Pentateuco. Segundo a hipótese mais aceita atualmente, os textos sobre pais e mães de Israel e os textos do êxodo não estariam unidos nos estágios oral e inicial de escrita da memória israelita - uma vez que essa memória destacava aspectos distintos conforme a tradição de diferentes tribos de Israel. Segundo Schwantes (2016, p. 117), os versos 2-8 teriam origem no período exílico, na região de Judá, expressão da esperança de retomada da terra que estava dominada pelos babilônios. Uma pista importante para situar as origens do texto é a ocorrência frequente da expressão "sabereis que eu sou YHWH vosso Deus" no livro de Ezequiel, um profeta levita que pregou em Judá logo após a conquista babilônia de 587 a.C. 
repetidamente se revoltando contra o seu Deus - mostrando que a libertação é um processo complicado, durante o qual é comum que o povo desanime e perca o rumo. A repetida menção da aliança nesta perícope é uma afirmação da fidelidade de YHWH aos pais e uma confirmação dessa fidelidade de Deus à geração do Êxodo - mesmo que os israelitas não se mantenham fiéis ao seu Senhor.

\section{Aspectos da teologia da perícope}

Tão importante quanto situar a perícope em seu livro, é situá-la em seu espaçotempo - em seu contexto. Neste artigo a perícope em seu lugar no Pentateuco ${ }^{7}$ e no contexto do período da redação ${ }^{8}$ do Pentateuco, que a maioria das estudiosas e estudiosos considera ser o final da dominação persa ou o início da helenista. Uma breve análise desse contexto mostra que o Pentateuco foi escrito em resposta a alguns desafios cruciais para a vida dos israelitas. ${ }^{9} \mathrm{O}$ primeiro grande desafio era o da reorganização e cuidado da terra de Judá, especialmente diante dos conflitos causados pelo retorno de parte dos exilados pela Babilônia. Como a terra havia sido ocupada pela parte do povo que não foi exilada pelos babilônios, o retorno de famílias exiladas provocava uma disputa pela posse e propriedade da terra, bem como pelo governo do povo na região.

Outro desafio importante, derivado deste primeiro, era o da identidade do povo de Deus. Quem era, de fato, israelita (no sentido teológico)? As diferentes memórias histórico-teológicas e as diferentes reivindicações pela terra e governo poderiam resultar em uma grave discórdia e eventual ruptura do povo (nos livros de Esdras e Neemias uma dimensão deste problema é abordada no tema da expulsão das esposas não-israelitas dos moradores da terra de Judá). Por fim, outro importante desafio era o da identidade do próprio Deus de Israel. Certamente havia discordâncias entre a parte do povo que ficou em Judá e a que foi exilada. Os que ficaram eram em sua maioria do interior de Judá, enquanto os exilados eram habitantes de Jerusalém, a maioria composta por membros dos grupos governantes do reino (membros da família real, lideranças militares e sacerdotais, chefes de famílias ricas que apoiavam a família real), mas também pessoas e famílias que trabalhavam para esses grupos. ${ }^{10}$

7 Isto não implica que haja no Pentateuco uma forma unitária de teologia, ao contrário, qualquer leitura mais atenta perceberá diversas tensões, diferenças e contradições entre textos do Pentateuco. Independentemente do processo histórico que levou à conclusão do Pentateuco, entendo que ele é fruto de um complexo consenso entre lideranças sacerdotais, escribas, profetas e representantes 'leigos' do povo israelita (não só dos residentes em Yehud) no período da dominação persa ou helenista. A bibliografia sobre o tópico é imensa. Um bom ponto de partida é a Knoppers e Levinson (2007).

8 O uso dos termos varia conforme os modelos de construção do Pentateuco: redação, composição, edição, colação. Uso o termo redação em seu sentido mais neutro, como equivalente da colocação do conteúdo em forma escrita.

9 Aqui também o uso dos termos é complicado. Do ponto de vista político e contextual, os destinatários primeiros do Pentateuco são os judaítas (moradores do antigo reino de Judá, agora parte de uma das províncias do Império Persa, mas uma subdivisão distinta da de Samaria que ocupava o território do antigo reino de Israel. Do ponto de vista teológico, porém, o Pentateuco sempre se refere ao povo de YHWH como israelitas (filhos de Israel). Assim, optei por usar os nomes em sua acepção teológica: Israel e israelitas.

10 Para uma visão geral do período, ver Kessler (2010) e Zabatiero (2013). 


\subsection{YHWH, Deus libertador e fiel}

Um dos temas principais, senão o principal, do Pentateuco é a identidade do Deus de Israel. Mesmo no período historicamente tardio da dominação persa, a questão da identidade de Deus permanece crucial para o povo de Israel e sua teologia. Particularmente neste período, após a destruição do Templo e o fim do reino de Judá, os israelitas se questionavam sobre o poder e a fidelidade de YHWH. Diferentes visões sobre quem é e o que faz YHWH povoavam a cultura e a prática religiosa em Israel. A perícope faz da identidade de YHWH o seu tema central, de modo que pode ser vista como uma espécie de material didático para os ouvintes do texto.

Há uma espécie de jogo teológico na perícope. Ela mostra que YHWH sempre foi o Deus de Israel, mas que ele não era ainda conhecido pelo seu nome no tempo dos pais e mães de Israel. 'El Shaday ${ }^{11}$ era o nome que se conhecia nos tempos de Abraão, Sara, Agar e seus descendentes. O relato do Gênesis mostra que 'El Shaday era um deus que acompanhava o seu povo, peregrinava junto com sua família e cuidava de seu sustento e proteção. Quando olhamos para as ações de 'El Shaday do ponto de vista abstrato, podemos dizer que ele era o deus da aliança, de fato, um deus que se comprometeu com as famílias de pais e mães de Israel, prometendo-lhes descendência e terra para viver bem. Em outras palavras, o deus da posteridade (descendência) e da prosperidade (terra). Como deus da aliança, 'El Shaday era descrito como um deus fiel que não desistia de suas famílias terrenas, mesmo quando aparentemente estava longe delas.

Possivelmente esta era a memória de clãs do interior de Israel nos tempos antigos, antes da monarquia e sua teologia unificadora. Essa memória não deveria incluir a saída do Egito, de modo que desde as origens das tradições que passaram a fazer parte do Pentateuco, se tornou necessário juntar a memória do campesinato que habitava em Canaã com a memória dos grupos que vieram do Egito após o Êxodo e se juntaram aos clãs que habitavam na terra para formar o povo de Israel. O recurso usado pelos redatores do Êxodo (e do Pentateuco) foi engenhoso: criaram uma linha do tempo da revelação de YHWH, mostrando que ele sempre foi o Deus de todo Israel, mesmo quando ainda não era conhecido pelo seu nome definitivo ('para sempre', 'de geração em geração' em Ex 3,15). A perícope visa, assim, reforçar essa identificação entre YHWH e 'El Shaday, já sugerida em Ex 3 (sem o nome 'El Shaday, mas com a expressão 'Deus de teus pais' e "Deus de Abraão, Isaque e Jacó').

Essa forma de falar a respeito de Deus pode parecer estranha, mas quando lembramos que nos tempos do antigo Israel a maioria dos povos e pessoas era politeísta e que tanto as famílias que ficaram em Judá quanto as que foram exiladas tinham de manter contato frequente com as diferentes divindades em Canaã e na Mesopotâmia, esta insistência do Pentateuco em reafirmar que YHWH é o único Deus de Israel fica mais compreensível. Servia, então, a duas funções: (a) reafirmar e reforçar a fidelidade exclusiva a YHWH como o único Deus de Israel e (b) mostrar que as diferentes 'teologias' dos israelitas se referiam a um único Deus e não a vários deuses. Chama a atenção o fato de que a afirmação de que YHWH não era ainda conhecido pelo seu nome no tempo dos pais e mães de Israel tem sido um problema exegético desde a Idade Média.

11 Sigo a proposta de transliteração em Kirshbaum et al. (2009). 
Desde comentaristas judeus medievais até a pesquisa acadêmica contemporânea atual ${ }^{12}$, o final do verso 3 tem sido interpretado como um corpo estranho: por que afirmar que o nome YHWH não era conhecido no tempo antigo, se ele aparece constantemente no livro de Gênesis? Todavia, quando lemos este verso junto com Ex 3,13 a estranheza desaparece. O problema está no modo como lemos os textos do Gênesis relativos aos pais e mães de Israel: o fato de o nome YHWH aparecer nos textos não quer dizer que os pais e mães de Israel o conheciam por esse nome - a presença do nome YHWH em Gênesis se deve à redação, não é a ipsissima vox dos pais e mães de Israel. Nas 'fontes' e no texto final do Exxodo era necessário anunciar o novo nome de YHWH à geração do Êxodo, pois ela ainda não o conhecia dessa forma. O uso do nome YHWH nos textos anteriores ao chamado de Moisés em Êxodo 3 é uma forma de ajudar destinatários e destinatárias da Torá a reconhecer que o seu Deus, YHWH, era o Deus criador do mundo e parceiro dos pais e mães de Israel, ainda que não conhecido plenamente nos tempos mais antigos. ${ }^{13}$

$\mathrm{O}$ foco teológico recai, então, sobre o nome YHWH e seu significado. A principal característica a ser destacada é a expressão $e u[s o u]^{14} Y H W H$, usada quatro vezes (v. 2.6.7.8). No Antigo Testamento essa expressão eu sou (mais nome) só é usada para se referir a Deus, com uma exceção. Em Gn 41,44 está presente na fala do faraó a José: "Disse ainda Faraó a José: Eu [sou] Faraó, contudo sem a tua ordem ninguém levantará mão ou pé em toda a terra do Egito." É claro que o uso aqui é proposital. O rei pode se considerar poderoso (e até divino em alguns casos), mas YHWH é ainda mais poderoso. O tom político está presente em ambos os usos. Ao afirmar "eu sou", o Faraó também delega poderes a José para governar o Egito durante o período da fome, de modo que um israelita salvará o povo egípcio da morte. Em Êxodo a situação é invertida: YHWH, o Deus dos hebreus $(3,18)$, libertará os israelitas da opressão do Faraó.

Além desse vínculo com Gn 41,44 também precisamos destacar o vínculo da expressão eu sou com o nome de Deus anunciado a Moisés em Ex 3,14 'ehyeh 'asher 'ehyeh, comumente traduzida por "eu sou o que sou". Se de Ex 3,14 em diante o significado do nome pode parecer um pouco ambíguo, aqui toda ambiguidade se desfaz e o sentido do nome YHWH fica evidente: YHWH é o Deus fiel (aliança) que liberta poderosamente o seu povo do poder imperial. Deve-se levar em consideração que o verbo hebraico traduzido por 'ser' (eu sou) não transmite a ideia de uma essência estática, ou de um 'ser' metafísico. É um verbo de ação, aponta para o que uma pessoa faz, ou para algo que

12 Este fato é notado por vários comentaristas em sua análise do verso. Por exemplo: Davies (2020).

13 Interpretação semelhante é feita por Ska (2011, p. 121, tradução minha): "Primeiro: o termo 'elohîm aparece na narrativa em um momento muito especial, no início do diálogo. Esta é a primeira vez que a divindade fala com Moisés. Este 'elohîm irá, mais tarde, revelar sua identidade em 3,6 e 14. Segundo, o texto insiste na identidade de 'elohîm com o 'Deus de teu pai' $(3,4)$ e com YHWH $(3,14$; cf. 3,15$)$. A estratégia é clara, pelo menos para mim. O texto usa o termo genérico em 3,4 porque os termos mais específicos virão mais tarde. A mesma estratégia é encontrada no texto sacerdotal Êx 6,2-4. Este texto usa três diferentes termos em poucos versos a fim de enfatizar a identidade de 'elohîm, o Deus da criação em P (6,2), com o El Shaday da aliança com os patriarcas $(6,3)$ e com o YHWH do êxodo (6.6; cf. 6,3.6.8). Aqui também o primeiro termo usado no texto é 'elohîm e é este 'elohîm que profere todo o discurso $(6,2)$ ".

14 Como é usual na gramática hebraica do período, o verbo de ligação não é usado, de modo que precisamos supri-lo em português. Seria possível, também, entender o hebraico como uma forma de aposto: eu, YHWH ..., mas embora gramaticalmente possível, essa opção não faz sentido nesta perícope. 
'acontece' - conforme indicam os léxicos e comentaristas, por exemplo, Schwantes (2016) e Davies (2020). Assim, as duas perícopes em conjunto transmitem a mesma ideia forte: YHWH é o Deus poderoso que liberta o seu povo da opressão (imperial ou não) em fidelidade ao seu compromisso com os pais e mães de Israel.

Temos, então, uma teologia da esperança libertadora. Em seu comentário a Êxodo 1-6 Milton (SCHWANTES, 2016, p. 118) assim destaca o sentido da expressão:

\begin{abstract}
A frase deseja, pois, afirmar algo peculiar: trata-se de uma fórmula de autoapresentação divina, que anseia por diferenciação. Através dela se confirma 'Javé' e, ao mesmo tempo, se diferencia e (!) se integra a experiência de Javé naquela de outros deuses. Em nossos v.2b-3 tanto se dão diferenciação ou especificidade (em especial nos v.6-8) quanto aproximação (em especial nos v.2-3)! Por meio do javismo, ocorrem, pois, simultaneamente, integração teológica e conflito.
\end{abstract}

Milton leu o texto em outro contexto histórico, mas sua percepção também é pertinente para o contexto pós-exílico da redação do Pentateuco: Israel precisava reafirmar e aprofundar sua própria versão da exclusividade e unicidade de YHWH, especialmente diante das versões babilônica e persa da vitória de seus próprios deuses diante de $\mathrm{YHWH}$ e seu povo.

A fidelidade de YHWH é destacada nos trechos da perícope que se referem à aliança (4-5, 7-8). Na primeira vez que a noção de aliança ocorre, ela se refere ao compromisso assumido por YHWH junto aos pais e mães de Israel em lhes dar uma nova terra para habitarem e viverem com dignidade. A geração no Egito, que ouve estas palavras de Moisés, certamente questionava a fidelidade de seu Deus, pois não estavam na terra que ' $E l$ Shaday havia jurado dar a seus antepassados e a ela mesma. $\mathrm{O}$ verso 5, portanto, declara que YHWH não se esquecera de seu juramento (promessa) e que essa lembrança estava na base de sua ação libertadora em benefício dos israelitas no Egito. No verso 7 a aliança com os antepassados é como que ratificada e atualizada para a geração do Êxodo através da expressão "tomar-vos-ei por meu povo e serei vosso Deus".

YHWH assume um novo compromisso, agora com a geração do Êxodo, e este compromisso atualiza a aliança com pais e mães de Israel: além de reafirmar a dádiva da terra (v. 8), YHWH mantém seu compromisso com esta geração libertando-a das mãos dos seus opressores. Assim, a revelação do sentido do nome YHWH fica completa: não só ele é o Deus que acompanha seu povo e jura ser fiel a ele (incorporando 'El Shaday), mas também como o Deus poderoso que liberta seu povo da opressão e mantém sua fidelidade, levandoo para a terra da antiga promessa. Para as gerações pós-exílicas, a mensagem é clara: também com elas YHWH mantem seu compromisso e fidelidade.

\title{
3.2 Libertação, aliança, terra
}

$\mathrm{Na}$ auto apresentação de YHWH, além de seu novo nome, recebe destaque a descrição de suas ações em benefício dos israelitas no Egito. A sequência de verbos que descrevem a ação libertadora de YHWH (v. 6-8) é emoldurada pela expressão eu sou YHWH (v. 6 e 8), além de aparecer também no verso 7 na declaração sobre o conhecimento de YHWH pelos israelitas. No centro da lista está uma versão peculiar da fórmula da aliança e sua implicação para a experiência de Deus, mostrando que ainda é a auto apresentação de YHWH que ocupa o centro das atenções: 
e vos farei sair de debaixo dos pesados encargos do Egito,

e vos libertarei de vossa escravidão,

e vos resgatarei com braço estendido e com grandiosas sentenças judiciais.

Tomar-vos-ei por meu povo e serei vosso Deus.

Então, sabereis que eu sou YHWH, vosso Deus, que vos faço sair de debaixo do pesado trabalho no Egito.

E vos farei entrar na terra a qual jurei, levantando a mão ${ }^{15}$, dar a Abraão, a Isaque e a Jacó;

e vo-la darei para a possuirdes.

Além da centralidade da revelação de YHWH, esta sequência de verbos também vincula fortemente o ato libertador com a promessa da terra (já presente no verso 4), de modo que revelação e terra se complementam. O conhecimento de Deus destacado no centro da perícope não é do tipo ritualístico, educacional ou místico. É conhecimento de Deus no chão da vida, no solo das experiências cotidianas da pessoa, no terreno árduo da dominação imperial. Deus se torna conhecido porque liberta e toma para si o povo, conduzindo-o à terra em que poderá viver com dignidade e liberdade ${ }^{16}$. O que está em jogo aqui é a construção da identidade do povo: a sua identidade não depende dos laços de sangue, do lugar específico de moradia, do vínculo a um governo. Israel é o povo da aliança de YHWH, ou seja, é um povo cuja identidade deriva da identidade de Deus, cuja ordenação política deriva da ação de Deus. Israel é Israel na medida em que é fiel - primeiro a YHWH, então uns aos outros.

Sete verbos descrevem a ação propriamente libertadora de YHWH: tirar, libertar, resgatar, fazer sair, fazer entrar, jurei dar, dar. Esta profusão de verbos, em seu conjunto, configura o significado da ação de YHWH. A libertação é um processo, cujo início é a derrota do poder que oprime e escraviza, a criação de um laço familiar (o verbo 'resgatar' é o mesmo usado para o resgate da terra do irmão falecido no livro de Rute) como fruto de uma decisão judicial efetiva que pode ser implementada ${ }^{17}$, a saída da situação de escravidão e a entrada em, e posse da terra que possibilita vida digna. $\mathrm{O}$ arranjo estrutural destes versos mostra que a libertação é processo subordinado à aliança de YHWH, que é representada aqui primariamente como um casamento (o verbo 'tomar' é usado frequentemente para se referir a casamentos; ver: DAVIES, 2020). Se já não estamos mais no tempo das

15 "Esta formula é usada em diversos contextos, refletindo diversos sentidos do gesto descrito (cf. BDB, p. 6701; TWAT 5, $640=$ TDOT 10, p. 37), mas como referência a um juramento ela aparece apenas em Ezequiel (sete vezes no cap. 20 e em 36,7; 44,12; 47,12), aqui e em Nm 14,30 (ambos P), Dt 32,40 (exílico?) e Ne 9,15 (talvez também Sl 106,26)" (DAVIES, 2020).

16 Pablo Andiñach também percebe esta dimensão do conhecimento de Deus em seu comentário de Ex 7,4: "finalmente, chama a atenção o fato de que o conhecimento de Deus [por parte dos egípcios] se dará quando o seu ato de libertação for visto. Não se trata de um conhecimento intelectual ou filosófico nem de uma percepção mística ou espiritual. Conhecê-lo-ão porque libertou os escravos. A identidade de Deus revela-se no feito de libertar os oprimidos" (ANDIÑACH, 2010, p. 115).

17 É a explicação de 'braço estendido e grandiosas sentenças judiciais'. Uma nota marginal: a expressão braço estendido, no Pentateuco, só é usada aqui e no Deuteronômio - bem próximo de uma expressão tipicamente 'sacerdotal'. Este é mais um indício de que decisões referentes às 'fontes' ou às 'origens' orais do texto do Pentateuco sempre serão aproximativas, uma vez que o trabalho editorial realizado é ainda mais complexo do que nossas teorias sobre a formação do Pentateuco dão a entender. 
'famílias' de pais e mães de Israel, mas no tempo do povo de Israel, este povo não pode perder a sua identidade familiar - daí a insistência, no livro do Êxodo, com a expressão filhos de Israel (que traduzi como israelitas) ${ }^{18}$. Estamos aqui no lugar da casa, não do Templo, nem do estúdio de escribas.

Independentemente das intenções de quem redigiu o Pentateuco em sua forma normativa no pós-exílio, esta perícope aponta para um fato essencial: não é a lei, não é o governo, não é o sacerdócio, não é o rei quem determinam o ser Israel - é YHWH, e YHWH somente. YHWH não é qualquer Deus. É Deus que liberta, dá a terra para Israel e o assume como seu próprio povo, sua família. Lei, culto, governo, sacerdócio estão subordinados à ação libertadora e dignificadora de YHWH em benefício de Israel - de todo o seu povo - que culmina na posse da terra prometida às famílias israelitas. O texto pode ter sido escrito por intelectuais, mas é a memória da casa de chão de terra que animou o seu conteúdo.

A perícope é parente de Êxodo 3, relato vocacional de Moisés que convoca a geração do Êxodo a participar em sua própria libertação. É parente, também, de outra memória subversivamente registrada e mantida na Torá: Ex 19,5-6 (na tradução de Almeida): "Agora, pois, se diligentemente ouvirdes a minha voz e guardardes a minha aliança, então, sereis a minha propriedade peculiar dentre todos os povos; porque toda a terra é minha; vós me sereis reino de sacerdotes e nação santa. São estas as palavras que falarás aos filhos de Israel". Se todo o Israel é reino de sacerdotes, não há mais privilégio para reis e sacerdotes. Se todo Israel é nação santa, não há mais possibilidade de se privilegiar uma família ou uma tribo ou uma profissão religiosa em detrimento de todo o povo. Toda a terra é minha, diz YHWH e é a sua palavra a única com autoridade sobre todo o Israel. As vozes delegadas não podem superar a voz originária. Assim resiste o Israel da terra, do chão, da plantação.

Em meio às ambiguidades da sua interpretação teológica do Pentateuco, Jean-Louis Ska reconhece este dado fundamental: "todo o Pentateuco está organizado em função da terra" (SKA, 2001, p. 314). Libertação, aliança e terra formam um conjunto teológico de primeira grandeza no Pentateuco, pois é este triângulo que revela YHWH ao seu povo e orienta a construção da identidade do povo ${ }^{19}$. Terra de Israel, terra das famílias israelitas:

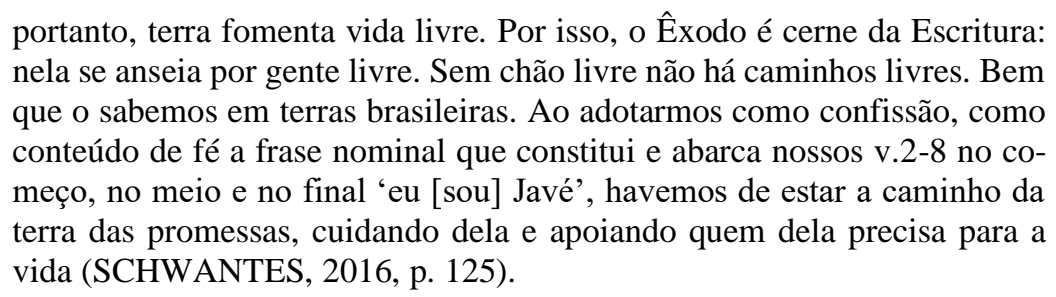

Terra recebida como doação é terra recebida para ser cuidada amorosamente. Assim se expressa o refrão de uma das mais lindas canções de Chico Buarque (letra) e Milton Nascimento (melodia): “Afagar a terra, conhecer os desejos da terra. Cio da terra a propícia

18 É possível que a ênfase na definição genealógica presente nos escritos cronísticos esteja ligada a esta forma de ver a identidade do povo - uma família de famílias. A posse da terra, herança de YHWH, só tem legitimidade dentro do âmbito da descendência familiar.

19 Este triângulo remete a outro, expresso na bela interpretação do livro de Rute pelo também querido mestre Carlos Mesters: pão, família, terra (MESTERS, 1991). 
estação, e fecundar o chão" ${ }^{20}$. No Êxodo se está muito longe da conquista imperial da terra. A terra prometida por YHWH à sua família não é terra de conquista (apesar da linguagem bélica do livro do Êxodo e, ainda mais evidente em Josué), é terra de dádiva, é terra para ser amada e cuidada como irmã, companheira que reparte a sua vida para que haja vida. Temos aqui a memória do campesinato judaíta que levou a público sua voz no processo de redação final do Pentateuco - a voz das elites não pode ser a única voz presente na Palavra de YHWH, em sua torá - a voz do povo também precisa estar lá - e, diremos nós, como voz dominante. Gemendo sob o peso da dominação imperial, as famílias judaítas que cuidavam da terra também tiveram de lidar com a volta de ex-governantes e elite que desejavam retomar os seus privilégios e o status quo ante. ${ }^{21}$

\section{Considerações finais}

Êxodo 6,2-8 nos convida a pensar em um novo modo de cuidar da terra, ao reconhecer que a terra é dádiva divina que revela a identidade de Deus e a do seu povo. Identidades não estáticas, não fixadas no tempo e no espaço, mas dinâmicas, construídas no movimento sociohistórico de viver e construir a vida comum. Comum, eis a palavra-chave desse novo modo de entender e cuidar da terra. Ela não é de ninguém, é de todos os seres vivos. Nem sequer da humanidade é a terra. Há de se renunciar ao antropocentrismo e aceitar que toda a vida na Terra é vida com direitos inalienáveis e partilhados com o ser humano.

Comum não lembra apenas comunismo (em sua forma mais bela e libertadora), de fato, vai além do sonho comunista e propõe um sonho comunitário, comunitariamente plural. Se nas décadas áureas da leitura popular e da teologia da libertação o comum estava subsumido à nova estrutura de um outro mundo possível, agora o comum se abre à pluralidade de sonhos e visões de outros mundos possíveis: sumak kawsai, ubuntu, terra sem males, democracia por vir - apenas algumas expressões de sonhos daqui e de lá também. Sonhos de gente de toda tribo, raça, cultura, povo, nação, identidade, opção, religião. Sonhos de gente que cuida e é cuidada. Sonho de gente que não deseja a tudo possuir, mas apenas almeja construir o sonho plural de outros mundos possíveis. 'El Shaday, YHWH, nomes plurais para um sonho plural. Sonho que até já foi canção:

O nome de Deus pode ser Oxalá

Jeová, Tupã, Jesus, Maomé

Maomé, Jesus, Tupã, Jeová

Oxalá e tantos mais

Sons diferentes, sim, para sonhos iguais. ${ }^{22}$

20 Em uma entrevista Chico assim explicou a origem da música: "Chico - Segundo o que eu sei, o Milton fez esta música pensando nos cantos de mulheres camponesas, que trabalham no Vale do Rio Doce. A música é muito complicada por possuir uma estrutura que a todo instante é quebrada, o ritmo é bastante solto. E isto, segundo o Milton, é pinto, perto do que ele ouviu por lá. São cantigas de trabalho, parece que eram mulheres que trabalhavam na colheita de algodão. A letra foi feita por mim pensando nisto. Cio Da Terra é uma canção de trabalho agrário" (BUARQUE apud GOLDZTEJN, 2021).

21 Esta atribuição do texto ao campesinato é uma hipótese baseada na linguagem e temática da perícope, levando em conta a interpretação da história do período, presente em Zabatiero (2013), caps. 8 e 9.

22 Gilberto Gil, Guerra Santa. 
Sonhos plurais, iguais no desejo de cuidar e não de explorar, de cuidar e não de conquistar, de cuidar e não de dominar.

\section{Referências}

ANDIÑACH, Pablo R. O livro do Exxodo: um comentário exegético-teológico. São Leopoldo: Sinodal/EST, 2010.

DAVIES, Graham I. A Critical and Exegetical Commentary on Exodus 1-18. Londres: T \& T Clark, 2020. E-book - Logos Bible.

GOLDZTEJN, Hélio. Notas sobre O cio da terra. Disponível em http://www.chicobuarque.com.br/construcao/mestre.asp?pg=notas/n_ocioda_77.htm. Acesso em: 21 out. 2021.

KESSLER, Rainer. História Social do Antigo Israel. São Paulo: Paulinas, 2010.

KIRSHBAUM, Saul; BLATITA, Dora F.; LANGER, Eliana R.; ARAÚJO, Reginaldo G. de. Transliteração do hebraico para leitores brasileiros. São Paulo: Ateliê Editorial, 2009.

KNOPPERS, Gary N.; LEVINSON, Bernard M. (Eds.). The Pentateuch as Torah. New Models for Understanding its Promulgation and Acceptance. Winona Lake: Eisenbrauns, 2007.

MEDINA, Richard W. La estructura sintáctica y la interpretación de Éxodo 6:2-9. DavarLogos: Revista bíblico-teológica, Libertador San Martín, v. 4, n. 2, p. 105-115, 2005.

MESTERS, Carlos. Como ler o livro de Rute: pão, família, terra. São Paulo: Paulinas, 1991.

SCHWANTES, Milton. Chamados à liberdade: comentário bíblico a Êxodo 1-6. São Leopoldo: Oikos, 2016.

SKA, Jean-Louis. Introducción a la lectura del Pentateuco: claves para la interpretación de los cinco primeros libros de la Biblia. Estella: Verbo Divino, 2001.

SKA, Jean-Louis. The Limits of Interpretation. In: DOZEMAN, Thomas B.; SCHMID, Konrad; SCHWARTZ, Baruch J. (Eds.). The Pentateuch. International Perspectives on Current Research. Tubinga: Mohr Siebeck, 2011. p. 109-122.

SOMMER, Benjamin D. Book or Anthology? The Pentateuch as Jewish Scripture. In: DOZEMAN, Thomas B.; SCHMID, Konrad; SCHWARTZ, Baruch J. (Eds.). The Pentateuch. International Perspectives on Current Research. Tubinga: Mohr Siebeck, 2011. p. 1091-1108.

ZABATIERO, Júlio P. T. M. Uma História Cultural de Israel. São Paulo: Paulus, 2013. 